\title{
STRATEGIC ALLIANCE IN THE CONSTRUCTION INDUSTRY: BARRIERS FACING ITS IMPLEMENTATION IN AN EMERGING MARKET
}

\author{
Funmilayo Iyabo BODUNDE ${ }^{1}$, Ebunoluwa Bimbola AKINRATA ${ }^{2 *}$, Ayodeji \\ Emmanuel OKE ${ }^{1}$, Ayotunde BABALOLA ${ }^{1}$
}

\author{
${ }^{1}$ Department of Quantity surveying, Federal University of Technology Akure, \\ Nigeria \\ ${ }^{2}$ Department of Quantity surveying, Ahmadu Bello University Zaria, Nigeria
}

Email: akinrataebun@gmail.com*

\begin{abstract}
Construction firms over the world involve in Strategy Alliance (SA) in order to achieve efficient time-cost-quality relationship during construction process through knowledge sharing, team culture and risk management with one another. Despite the numerous benefits gained, there are still various barriers facing it in the developing world. This paper is aimed at analysing the current level of awareness and barrier facing SA procurement method in the building industry in an emerging market (EM) using Nigeria as a case study, to profound future steps in avoiding these barriers and to encourage maximum implementation in the construction industry. A survey design was employed in evaluating the level of awareness of SA and barriers facing its adoption in building industry. Construction professionals in Nigeria were examined through a well-structured questionnaire. Mean Item Score and Factor Analysis were utilized in evaluating data gathered on the current barriers to SA procurement method in the construction industry. It was revealed from the study that the awareness level of SA procurement method within the industry amongst construction professionals is moderately high. This indicates that the barrier facing SA procurement method is not the issue of awareness but of willingness to adopt it. It was also established from the study that fear and trust issue, lack of strategic planning toward alliance, inadequate knowledge about alliance and, different in cultural values were the major component barriers facing strategic alliance procurement method. The study shows the true reflection of the current barriers facing the adoption of SA procurement methods in the developing country and notable points in this study can be largely recommended to promote strategic alliance partnership among construction firms the Nigerian construction industry and other emerging economy countries were building projects are carried out in the same approach, style and method.
\end{abstract}

Keywords: Strategic Alliance, Partnership, Barrier, Professional, Factor analysis, Construction industry.

\section{INTRODUCTION}

There has been a lot of discussions for a long period of time among stakeholders in the construction sector on ways in improving the workforce, increasing performance and productivity (Burke and Morley 2016). This brings about the introduction of various interorganization partnership within the construction industry, which makes the familiar pattern of one company doing everything in its own right outdated. The requisite technology, financial and competitive skills, sources of sharing in the global construction market (workmanships, machinery, equipment, and more) made many construction firms enter into 
relationships to compete with other firms. For over five decades now, this interactive contracting approaches like joint venture, partnering, relationship management and Strategic Alliance (SA) have been gaining momentum in the construction industry. According to Howarth, Gillin and Bailey (1995), "strategic alliance is a co-operative arrangement between two or more organizations that forms part of, is consistent with their overall strategy, and contributes to the achievement of their major goals and objectives". In most of the developing countries, SA method of procurement operates in the construction industry through companies working together to increase their complementary capacity to execute heavy, complex and risky (Ngowi, 2007). As stated by Nielsen and Neergaard (2018), SA occurs mostly in some cases where costs/risks are too high to become feasible for a company to bear. Furthermore, inter-organization partnership, such as SA has become essential tools for business administration in the building sector, particularly in dynamic and rapidly changing environments and, in enhancing competitiveness ability of companies. It has contributed to bridging the gaps between the existing company resources and its future expectations (Burke and Morley, 2016).

Various forms of strategic alliances have been adopted globally as a joint tactic among several organizations (Andersson and Görgulu, 2014). In an Emerging Market (EM), alliance has become vital strategic manoeuvres in the building industry, which is formed with the intent of achieving innovation, knowledge and, utilizing a prequalified pool of other contractors to achieve a certain goal. According to Faems and Van Looy (2003), construction companies tend to involve in SA in order to improve over time in sharing knowledge, team culture and, risk management. As stated by Van den Berg and Kamminga (2006), SA procurement process is an excellent way of achieving efficient time-cost-quality relationship during the construction process. Furthermore, it offers construction firms with several advantages such as; exposure to new events and innovations, complementary tools, markets and emerging developments, which in turn improve the capacity of the company to research, take advantage of economies of scale, share risks and externalize different operations in the value chain (Gulati, 2007). In addition, the construction projects under SA management get a mutual vision, procurement efficiencies and early participation of contractors.

Despite the global advantage of SA adoption in the construction industry, Ofori (2000) stated that the industry is still facing a wide range of problems due to inadequate implementation of projects in developing countries. In a bid to solve these problems, Burke and Morley (2016) suggested that construction companies need good administration, different procurement method, resources, skills and healthy alliance (within and outside the construction industry) for successful delivery. With the adoption of a strategic partnership in the construction sector, these resources and capability needed can be easily acquired. According to Tavallaei, Hosseinalipour and Mohebifar, (2017), the implementation of strategic alliances in the construction industry in the developing world has been facing various difficulties over the last decade. This seeks for an investigation to SA procurement method in the construction industry in an Emerging Market (EM), in order to provide an update on the current level of awareness of SA procurement method and the current barriers facing its implementation. On this basis, the paper aims to evaluate the awareness level and barriers to the adoption of strategic alliance procurement method in the construction industry using Nigeria as a case study, with a view to develop potential steps to overcome these obstacles. Consequently, this study reflects a true representation of barriers facing strategic alliance in a developing world, and recommendations from the study will be useful in fostering strategic partnership in Nigeria and other developing countries where construction activities are being carried out using a similar method, strategy and style.

\section{REVIEW OF RELATED LITERATURE}

According to Tavallaei et al. (2017), strategic alliance is a type of cooperation networks which can be described as a kind of contract arrangement were partners invest their resources for 
a limited period of time to achieve their mutual objectives and goals. This was buttressed by (Išoraitè, 2009) that SA is a cooperative arrangement between two or more organizations for one specific business operation so that each company can benefit from the strengths of the other to achieve competitive advantage. Most of the time, strategic alliance works like a joint venture, but an alliance always involves competitors and has a shorter lifetime (Išoraitè, 2009). In strategic alliances, managing partnership/alliance may be greatly affected by each of the partners' commitment, and although not only via participation, partners are expected to involved technically and financially (Nguyen, 2019). According to Van den Berg and Kamminga (2006), the establishment of strategic alliances was seen as responding to globalization, growing market instability and complexity. Nurullah et al. (2012) was able to proposed a strategic alliance conceptual model that provides the holistic approach that focuses on the dimensions of the procedures, using various models and approaches to alliances. The model proposed contains the following elements: top management; preparation; intellectual foundations that support the strategic alliance field; Partner selection, team integration and assessment of alliance objectives; Pre-evaluation; Analysis and assessment of the alliance's mutual needs and requirements. Adopting this model in the construction industry, especially in an emerging market will help in minimizing various barriers been faced when entering into strategic alliance.

Akiner and Yitmen (2011) submitted that contractors in the construction industry combine forces together to form SA, so as to build on each other complimentary work and capabilities. This happens when the risk is too high to be viable for one construction firm. Ngowi (2007) opined that the subsequent globalization, together with the exceedingly fragmented and disruptive nature of construction, has forced the industry in seeking for management approaches such as strategic alliances, in order to build on the abilities and strength of different construction participants in achieving its goals. According to Chang and Hsin (2006), many international firms have several alliances with local firms to shape global partnerships. Although implementing strategic alliances in the construction industry have addressed opportunities for knowledge management and learning (Grant and Baden-Fuller, (2004) and Ingirige and Sexton, (2006)), strategic alliances have been widely debated since the interim cooperation has developed into an essential factor for creating competitive advantage globally $(\mathrm{Xu}, 2005)$. Studies that focus on the level of adoption and barriers facing its full implementation in the construction sector, especially in an emerging market economy country are still scanty.

\subsection{Reasons for Strategic Alliance}

Several works of literature have highlighted the various reason for adopting a strategic alliance. As for Akiner and Yitmen (2011), the growth opportunity is one of the key reasons why many companies adopted strategic alliance, which allow business activities to develop faster than normal by using its distribution networks in combination with the advantage of a good brand image with other companies in alliance. Stanek (2004) summited that most organizations form collaborations (SA) to develop, open up new markets, resolve local market constraints, and to share mutual benefit \& risk. Fitzpatrick and Dilullo, (2005) opined that productive alliances bring forth innovation, open communication, trust, interdependence, engagement, cooperation, alignment of goals and joint solution of the problem for the companies involved. In addition, Mills, Nalewaik, and Davis (2016) argued that sharing skills (distribution, marketing and management), products, customer awareness, technological expertise and assets contributes to a synergistic impact, leading to a pool of resources more precious than separate single resources in the business concerned. According to Raue and Wieland (2015), the key reasons for strategic alliance were creativity, cost and exposure to capital, direct accessibility to target markets, economies of scale and competitive gain. 


\subsection{Some Barriers facing strategic alliance}

Based on the recent literature on the rudiments that might hinder strategic alliances in building industry among developing countries (Holt, Love and Li, (2000); Yi Wei, (2007); Andersson and Görgulu, (2014); Zamir, Sahar and Zafar, (2014); and Nielsen and Neergaard, (2018)). It is clear that there are some reflections that stand out, which is the challenge in choosing the right partner when entry into strategic alliance (John, 2011). The very first step of choosing a partner starts the challenge to strategic alliance faced by companies involves. Choosing the wrong partner will be detrimental to any alliance. As stated by Grant and Baden-Fuller (2004), an alliance has no basis to build on without a certain degree of confidence and integrity, and once the parties involve is disintegrated, SA will become an history. So, it is crucial for all parties entering an alliance to clearly and concisely identify their expectations. Burke and Morley (2016) indicated that lack of adequate knowledge and proper evaluation are challenges been faced in strategic alliance, it is necessary to know when to re-evaluate the alliance and adjust the structure in order to ensure that a commercial relationship continues to support both sides. Both companies involve in alliance must realize that change is inevitable and over time, they must cooperate in order to reach new agreements. Other barriers are distrust of ownership and control issues (Bamford and Ernst, (2005); loss of Opportunity cost (Burke and Morley (2016); resistance to change (Bamford and Ernst (2002a); uneven alliance; fear of undisclosed agendas (Raue and Wieland (2015); risk of sharing proprietary information; fear of future mergers (Fitzpatrick and Dilullo, 2005); staff turnover; trust issues and ego (Bamford and Ernst, 2002b); managing the alliance (Artto and Kujala, 2008).

\section{RESEARCH METHODOLOGY}

This paper aims to identify obstacles to the strategic alliance procurement method in construction performance in the developing world, in order to profound possible measures to prevent these barriers and increase its adoption. This study was carried out in Nigeria, and the respondents were gathered from the six states of the southwestern zones in the country. Southwestern states were chosen because the zone has the highest level of construction activities in Nigeria. A survey approach was adopted in this study; professionals like Builders, Architects, Quantity Surveyors (QS) and Civil Engineers that are unswervingly involved in the construction activities were sampled. Information about these professionals was collected from their respective organizational bodies. According to the state chapters of construction professionals as at December 2019, five thousand four hundred and five (5405) professionals from organizations in the construction industry both contracting and consulting firms in five states in Southwestern part of Nigeria which are Lagos, Oyo, Ondo, Osun and Ekiti States. The required sample size from this sample frame was derived by means of a demographic formula by Yamane (1967). Total numbers of 401 respondents were sampled after using formula. The sample size for this study was determined using these formulae;

$$
\mathrm{n}=\frac{N}{1+N(e)^{2}}
$$

Where

$\mathrm{n}=$ Sample size

$\mathrm{N}=$ Number of respondents

$\mathrm{e}=10 \%$ level of precision which is $\pm 10 \%$. (Yamane, 1967)

Four hundred (401) copies of the questionnaires were sent to the respondents, and three hundred and sixty-three (363) valid response were retrieved back from them. Based on this result, the response rate for the questionnaire was approximately 91 per cent, which is 
certainly appropriate for analysis. The questionnaires were self-administered through handto-hand and online, while the collection of data covered four months and three weeks. For the purpose of this study convenience sampling was used as a procedure for selecting a sample from the entire population in such a way that every member of the population has a chance in selecting the sample.

For this study, a structured questionnaire was used as a research instrument. The questionnaire was built based on information gathered from the literature review. This questionnaire was prepared in sections, with the first part designed to gather information about the respondent's background. While the second section dealt with barriers facing strategic alliance procurement method in the construction industry. A pilot analysis performed to pre-test the information gathered from the literature review. It was accomplished by randomly dispatching twelve questionnaires to some selected construction professionals (both academia and experienced) for face validity, and the outcome of the pilot test/ Face validity was used in updating the final draft questionnaire. This was carried in line with Sushil and Verma (2010) suggestion that the authenticity of the face validity should be checked by qualified experts who will review the material content to verify if the items are relevant. Ultimately, 20 out of 28 identified barriers facing strategic alliance were considered face accurate for the final questionnaire.

Frequency and percentage were used in analysing the respondents' background information (see table 1). For the second section of the research instrument, Mean Item Scores (MIS) and Factors Analysis (FA) were used in analysing the information gathered. Furthermore, Cronbach's $\alpha$-test for this study was also carried out to assess the research instrument's reliability. This approach is done by measuring the questionnaire's reliability across each field and the mean of the questionnaire's whole fields. Cronbach's $\alpha$ standard value scale ranges between 0 and 1 , and the closer the value to 1 , the greater the degree of internal accuracy. The Cronbach's $\alpha$ value for this study is 0.897; this indicated that the instrument used was remarkably accurate as the instrument's degree of reliability becomes more optimal, i.e., the value tends toward 1.

\section{FINDINGS AND DISCUSSION}

\subsection{General information of respondents}

The result in Table 1 displayed the respondents' general information. The information was based on the respondents' background. Information obtained from this table provided a quality check to the data gotten from the respondents. Table 1 established that Quantity Surveyors and Architects that responded to the questionnaire represented 35.2\% and $28.1 \%$ respectively. $16.5 \%$ were Builders, while $20.2 \%$ of respondents were Civil Engineers. This showed that the respondents were from all relevant construction professionals who are currently practising in their respective states. The data showed that all respondents were under their professional membership. $35.2 \%$ were a member of NIA, while $28.1 \%$ of respondents fall under the membership of NIQS. It was established that $20.2 \%$ of respondents were under the umbrella of NSE. Moreover, $14.8 \%$ were under NIOB, while $1.7 \%$ fall under other professionals not stated. The analysis of respondent's category/grade of membership showed that $38 \%, 61.4 \%, 0.3 \%$ and $0.3 \%$ of respondents were probationers, Corporate/Associate members, fellows and others respectively. This means that the respondents were qualified to provide information on the subject of strategic alliance procurement method in the construction industry. Corporate/Associate members had the largest percentage because they are mostly active on site.

Table 1 showed that $3 \%$ and $12.7 \%$ of the respondents were polytechnic graduates who are OND and HND, respectively. The highest number of respondents were those with Bachelor Degree (B.tech \& B.sc), which represented 65.6\%. Moreover, $15.7 \%$ and $3 \%$ were M.sc/M.tech and PhD respectively. From the information on the academic qualifications of 
the respondents, it can be concluded that these professionals possessed satisfactory academic training to supply data for this study. The table further reveals that $20.9 \%$ of the respondents had executed 76 projects in the last 5 years, and $79.1 \%$ had executed 287 projects in 6 years above. The above analysis indicates that majority of the sampled respondents were educated construction industry practitioners, experienced and had handle series of projects in years back does make them suitable to give adequate information on the strategic alliance contract in the construction industry.

Table 1: Profile of the Respondents

\begin{tabular}{|l|l|c|c|}
\hline Background Characteristics & & Frequency & Percentage \\
\hline Profession of respondent & Architect & 128 & 35.2 \\
& Quantity Surveyor & 102 & 28.1 \\
& Builder & 60 & 16.5 \\
& Civil Engineer & 73 & 20.2 \\
& Total & $\mathbf{3 6 3}$ & $\mathbf{1 0 0}$ \\
\hline Professional membership & NIA & 128 & 35.2 \\
& NIQS & 103 & 28.1 \\
& NSE & 73 & 20.2 \\
& NIOB & 53 & 14.8 \\
& Others & 6 & 1.7 \\
& Total & $\mathbf{3 6 3}$ & $\mathbf{1 0 0 . 0}$ \\
\hline Category/Grade of membership & Probationer & 138 & 38.0 \\
& Corporate/Associate & 223 & 61.4 \\
& Fellow & 1 & 0.3 \\
& Others & 1 & 0.3 \\
& Total & $\mathbf{3 6 3}$ & $\mathbf{1 0 0 . 0}$ \\
\hline Highest academic qualification of & OND & 11 & 3.0 \\
respondent & HND & 46 & 12.7 \\
& B.Sc/B.Tech & 238 & 65.6 \\
& M.Sc/M.Tech & 57 & 15.7 \\
& Ph.D & 11 & 3.0 \\
& Total & $\mathbf{3 6 3}$ & $\mathbf{1 0 0}$ \\
\hline Project Executed & $1-5$ years & 76 & 20.9 \\
& 6-10 years & 89 & 41.9 \\
& $11-15$ years & 34 & 24.5 \\
& $16-20$ years & 12 & 9.4 \\
& Over 20 years & $\mathbf{8 . 7}$ & 3.3 \\
& Average & & \\
\hline
\end{tabular}

\subsection{Level of Awareness of Strategic Alliance Procurement in the Construction Industry}

The first objective of this study was to assess the level of awareness of strategic alliance procurement method in the construction industry within the study area. The result was presented in Table 2.

Selected construction professionals were asked to indicate their level of awareness of strategic alliance in the construction industry in their respective states according to their experience and knowledge about strategic alliance on a five Likert scale ranging from 1(very low) to 5 (very high). As shown in Table 2 , the level of awareness of strategic alliance procurement method in the construction industry among the developing countries showed that most of the construction professionals have moderately high awareness level about strategic alliance procurement method within the industry. 
Table 2: Level of Awareness of Strategic Alliance in the Construction Industry

\begin{tabular}{|c|c|c|c|c|c|c|c|}
\hline & Very low & Low & $\begin{array}{c}\text { Moderately } \\
\text { high }\end{array}$ & High & $\begin{array}{l}\text { Very } \\
\text { high }\end{array}$ & Mean & Indication \\
\hline Lagos & 9 & 47 & 58 & 9 & 5 & \multirow[b]{6}{*}{$\nabla$} & \multirow[b]{6}{*}{$\nabla$} \\
\hline Ogun & 4 & 27 & 39 & 5 & 2 & & \\
\hline Oyo & 2 & 11 & 34 & 7 & 3 & & \\
\hline Ondo & 1 & 9 & 29 & 3 & 1 & & \\
\hline Ekiti & 1 & 5 & 17 & 1 & 0 & & \\
\hline Osun & 1 & 8 & 22 & 4 & 0 & & \\
\hline Total & $18(4.9)$ & $107(29.5)$ & $199(54.9)$ & $28(7.7)$ & $11(3.0)$ & 3.21 & $\begin{array}{c}\text { Moderately } \\
\text { high }\end{array}$ \\
\hline
\end{tabular}

\subsection{Barriers Facing Strategic Alliance Procurement in the Construction Industry}

Given the number of barriers reported by literature, some barriers may result in more accurate intrinsic effects in this study. The outcome of reviewed literature identified twenty (20) barriers facing strategic alliance, and these barriers were also verified by selected professionals after face validity for the research instrument. As presented in Table 3, was the mean analysis of the respondent's perceptions on the barriers of strategic alliance procurement method in the construction industry. Mean analysis was used in ranking the barriers, while Standard Deviation was used for situations where two variables have similar mean value.

Table 3 contains responses from respondents to barriers facing SA procurement method in the Nigerian construction industry. Results show that the mean value of each item in the table is $\geq 3.00$. On the basis of the Likert scale of 5 points, the 2.50 scoring is usually seen as average, but a score of 3.00 indicates that respondents generally believe the barriers of the strategic alliance procurement method are relevant to the construction industry. The top four barriers are resistance to change from the traditional method with mean 4.16 was ranked first ( $1^{\text {st }}$. This implies that resistance to change from the traditional method is the topmost barrier facing SA in the study area. This corroborated with Love et al., (2015) that compatibility between partners depends on the willingness to adapt, the incorporation of alliance management skills in a partner culture structure, good leadership consequence and, above all, alliance preparation may be attributed variously to the effectiveness of strategic alliances. In the construction industry, strategic alliances are not quick and easy to establish, fund and build between the firms. It takes time to change and revise many job descriptions of many positions which mostly lead to resistance to change from the traditional method. Fear of job loss after alliance ranked top among the barriers to SA with mean 4.14. The misconception of losing their job due to incompetency after alliance tend to act as a barrier to the adoption of strategic alliance procurement method. The third $\left(3^{\text {rd }}\right)$ on the ranking was alliance management issues, with mean value 4.11. This follows decades of mistrust and hostility, which occurs in strategic alliance projects in the past. As stated by Lahdenperä (2009), only through full cooperation and alliance between the participating construction firms can the development of attitudinal shifts towards one mutual trust and harmony be achieved. 
Table 3: Barrier Facing Strategic Alliance procurement method in the Construction Industry

\begin{tabular}{|l|c|c|c|}
\hline Barriers & Mean & Std. Deviation & Ranking \\
\hline Resistance to change from the traditional method & 4.16 & 2.956 & 1 \\
\hline Fear of job loss after alliance & 4.14 & 1.207 & 2 \\
\hline Managerial issues during alliance & 4.11 & 1.164 & 3 \\
\hline Loss of opportunity cost & 4.07 & 0.920 & 4 \\
\hline Egoism & 4.05 & 1.146 & 5 \\
\hline Fear of future mergers & 4.04 & 1.246 & 6 \\
\hline Greediness & 4.01 & 0.835 & 7 \\
\hline Staff turnover after alliance & 3.98 & 1.192 & 8 \\
\hline Uneven alliance qualification & 3.87 & 0.790 & 9 \\
\hline Risk of sharing proprietary information & 3.87 & 1.228 & 10 \\
\hline Different style of management & 3.81 & 1.085 & 11 \\
\hline Disparities in skills and roles to play in alliance & 3.78 & 1.323 & 12 \\
\hline Legal liability & 3.72 & 1.150 & 13 \\
\hline Fear of future failure & 3.69 & 1.074 & 14 \\
\hline Inadequate knowledge about alliance & 3.68 & 1.149 & 15 \\
\hline Risk that partners defaulting promise and agreement & 3.59 & 1.103 & 16 \\
\hline Commitment level & 3.56 & 1.057 & 17 \\
\hline Fear of uneven risk sharing and allocation & 3.50 & 1.097 & 18 \\
\hline Differences in cultural values & 3.42 & 1.070 & 19 \\
\hline Fear of hidden agenda toward alliance (Trust issues) & 3.38 & 1.075 & 20 \\
\hline
\end{tabular}

\section{Factor Analysis}

Factor analysis of barriers facing strategic alliance procurement method in the construction industry was undertaken. Taking into account the number of barriers reported in the literature, it is likely that other barriers of SA would have similar underlying effects. So, in order to reduce these barriers into a smaller number of consistent explanatory variables, factor analyzes were deemed necessary. As shown in Table 4, the Kaiser-Meyer-Olkin (KMO, o.883) sampling adequacy test for this study revealed that data obtained was adequate for analysis and the Bartlett sphericity test was highly relevant as regards the correlations between variables as suggested by Tabachnick and Fidell, (2007).

Table 4: KMO and Bartlett's Test

\begin{tabular}{|l|l|c|}
\hline Kaiser-Meyer-Olkin Measure of Sampling Adequacy. & 0.883 \\
\hline Bartlett's Test of Sphericity & Approx. Chi-Square & 826.594 \\
\cline { 2 - 3 } & Df & 352 \\
\cline { 2 - 3 } & Sig. & .000 \\
\hline
\end{tabular}

According to Pallant (2005), one of the purposes of factor analysis is to extract factors that better demonstrate this correlation. For this factor model to be accurate, the variables must be linked to one another. The correlation matrix of the 20 variables constituting the barriers facing SA procurement method in the construction industry was done, and five principal components with their own Eigenvalues greater than 1.0 were extracted as shown in Table 5. These factors are arranged in descending order of variance explained. The first five elements reflect approximately $65 \%$ of the overall variance. The remaining fourteen items make up just $35 \%$ of the variance. 
Table 5: Total Variance Explained on Barriers of Strategic Alliance in Construction Industry

\begin{tabular}{|l|c|c|c|c|c|c|c|c|c|}
\hline \multirow{2}{*}{ Component } & \multicolumn{4}{|c|}{ Initial Eigenvalues } & \multicolumn{3}{c|}{$\begin{array}{c}\text { Extraction Sums of Squared } \\
\text { Loadings }\end{array}$} & \multicolumn{3}{c|}{$\begin{array}{c}\text { Rotation Sums of Squared } \\
\text { Loadings }\end{array}$} \\
\cline { 2 - 11 } & Total & $\begin{array}{c}\text { \% of } \\
\text { Variance }\end{array}$ & $\begin{array}{c}\text { Cumulative } \\
\%\end{array}$ & Total & $\begin{array}{c}\text { \% of } \\
\text { Variance }\end{array}$ & $\begin{array}{c}\text { Cumulative } \\
\%\end{array}$ & Total & $\begin{array}{c}\text { \% of } \\
\text { Variance }\end{array}$ & $\begin{array}{c}\text { Cumulative } \\
\%\end{array}$ \\
\hline 1 & 7.772 & 38.860 & 38.860 & 7.772 & 38.860 & 38.860 & 4.265 & 21.327 & 21.327 \\
\hline 2 & 1.606 & 8.031 & 46.891 & 1.606 & 8.031 & 46.891 & 3.510 & 17.551 & 38.879 \\
\hline 3 & 1.256 & 6.282 & 53.173 & 1.256 & 6.282 & 53.173 & 2.028 & 10.139 & 49.018 \\
\hline 4 & 1.184 & 5.919 & 59.092 & 1.184 & 5.919 & 59.092 & 1.807 & 9.036 & 58.054 \\
\hline 5 & 1.068 & 5.338 & 64.430 & 1.068 & 5.338 & 64.430 & 1.275 & 6.377 & 64.430 \\
\hline
\end{tabular}

After the correlation matrix analysis for factor extraction revealed five (5) underlying factors with values of Eigen greater than 1.0. Table 5 was able to display the top 5 variances of the 20 linear components in the data set with the corresponding value of each independent variable as described by that particular linear component. This was done to reduce the lengthy size of the table by removing data that are not useful for the study. The factor grouping based on the varimax rotation is shown in Table 6. Factor 1 accounted for $38.86 \%$, while factor 2, 3, 4 and 5 accounted for $8.03 \%, 6.28 \%, 5.92 \%$ and $5.34 \%$ respectively of the total variance. With the outcomes in Table 5 and as a reminder, the KMO value of 0.883 $(88.3 \%)$. This showed that factor analysis sampling is suitable for this study.

\subsection{Discussion of factor extraction}

Before discussing the factor extracted, it is important to name these factors before interpreting the five (5) physical components extracted. The name is subjective, depending on the analyst's background and training. No scientific procedure is available to determine those factor names. Therefore, the thoughtful naming of these factors was deemed to be appropriate for this study. Each factor is labelled and interpreted as follows: i) Fear and trust issue, ii) Lack of strategic planning toward alliance, iii) Inadequate knowledge about alliance, iv) Managing the alliance and v) Different in the style of management and cultural values

Fear and Trust issue explained by the first component, this principal factor accounts for $38.86 \%$ of the overall variance observed and comprises five items. The items are fear of hidden agenda toward alliance (trust issues), risk that partners defaulting promise and agreement, risk of sharing proprietary information, fear of uneven risk-sharing and allocation, egoism, and fear of job loss after alliance. When entering into strategic alliances in the construction industry, fear and control issue are inextricably linked to risk. Therefore, organizational parties involved in the alliance must learn the ties between trust, control and risk, which is very important. This result (fear and control issue) agreed with Das and Teng (2001) that the problem of trust definition remains largely unresolved in strategic alliance, and this serves as a barrier for potential organizational parties in forming alliance. According to McEvily, Perrone, and Zaheer (2003), Schoorman, Mayer, and Davis (2005), the readiness for vulnerability among the parties may be considered to be the core of trust when going into alliance in the industry. So, therefore, positive perceptions of all parties' capacity, benevolence and comprehensiveness will constitute a contribution to that willingness in form successful alliance in the construction industry, and risk-taking is the product of that willingness when constituting such alliance. Hameed and Abbott (2017) opined that trust must include insight, willingness, intentionality, and good conduct for parties involved in SA to be successful.

The second principal factor is labelled "Lack of strategic planning towards alliance". As shown in Table 6, this factor accounts for $8.03 \%$ of the total observed variance and contains six items which can be regarded to as lack of strategic planning, being one of major barriers facing strategic alliance procurement method in the construction industry. The items under this category are: commitment level, fear of future mergers, fear of future mergers, legal 
liability, loss of opportunity cost, uneven alliance qualification, and greediness. The key exponent of formalization of inter-organizational alliance/partnerships is contract-strategic planning, which applies "projecting exchanges into the future". Alliance contracting is primarily intended to reduce opportunistic behaviour and establish leverage over partner firms, transaction cost economists and agency theorists claim. So, inadequate strategic planning before entering into alliance in among firms in the construction industry is a great threat to SA procurement method. Strategic planning in SA increase cost-effectiveness activities over self-interest, changing pay structures and incentives, and increasing transparency in relations and monitoring objects (Lui and Ngo, 2004). This will therefore eliminate the fear of future mergers, loss of opportunity cost, uneven alliance qualification from mind the parties.

The third major barrier facing SA is known as Inadequate knowledge about alliance. This factor constitutes $6.28 \%$ of the total variance observed and consists of three components. The loads for the variables are recorded; inadequate knowledge on alliance, fear of future failure, and resistance to change from the traditional method. This result buttressed Burke and Morley (2016) that resistance to change and cultural problems in alliance formation are caused by chauvinism, inadequate knowledge on alliance and, diverse approaches toward business (project). The lack of knowledge and realization of the existence among the construction firms in the developing countries eventually affects the level of knowledge of the benefits they could derive from its implementation in the construction industry. In the Emerging Market (EM), most construction companies find it difficult to change from the conventional method of executing the project. Therefore, if strategic alliance procurement method is to operate maximally in the construction industry, it is necessary to increase awareness between all construction organizations as the benefits can be demonstrated.

The fourth principal factor is tagged "Managing the alliance". This factor is seen as one of the most significant factors in the general rating shown in Table 6. The component also comprises three items and constitutes $5.92 \%$ of the overall variance observed. The following items are listed: managerial issues during alliance, disparities in skills and roles to play in alliance, staff turnover after alliance. As long as partners in construction firms agreed to develop a strategic alliance partnership among themselves, both partners will face significant difficulties in turning their positive intentions into a profitable enterprise on all levels from routine to strategic planning through the management of this alliance. This alliance management process requires that two construction companies combine all human and material resources, establish a realistic governance framework with adequate power and control and learn to cooperate. To pick liaison management personnel and members, "continuous linkages between partners, companies and the alliance required" constitute the major barriers facing SA in the construction industry, and this must be carefully addressed between the parties (Artto and Kujala, 2008). This managing skill is found wanted among construction companies in the developing countries.

The fifth principal factor is tagged "Different styles of management and cultural values" which contains a different management styles and differences in cultural values. This principal factor accounts for $5.33 \%$ of the total observed variance. Partner organizations in alliance within the same country sometimes have diverse cultural value, beliefs, climates and expectations, which is one of the key challenges faced by strategical alliances in the construction industry. This fact buttressed Zamir, Sahar and Zafar (2014) that cultural differences pose a great risk for strategic partnership because cultural conflicts and different thought can create a condition in which parties in organizations disagree with certain aspects agreement. 
Table 6: Rotated Component Matrix on Barriers of Strategic Alliance in the Construction Industry

\begin{tabular}{|c|c|c|c|c|c|}
\hline \multirow[b]{2}{*}{ Barriers } & \multicolumn{5}{|c|}{ Component Factors } \\
\hline & 1 & 2 & 3 & 4 & 5 \\
\hline \multicolumn{6}{|l|}{ 1) Fear and trust issue } \\
\hline $\begin{array}{l}\text { Fear of hidden agenda toward alliance (Trust } \\
\text { issues) }\end{array}$ & 0.868 & & & & \\
\hline $\begin{array}{l}\text { Risk that partners defaulting promise and } \\
\text { agreement }\end{array}$ & 0.795 & & & & \\
\hline Risk of sharing proprietary information & 0.772 & & & & \\
\hline Fear of uneven risk sharing and allocation & 0.714 & & & & \\
\hline Egoism & 0.619 & & & & \\
\hline Fear of job loss after alliance & 0.544 & & & & \\
\hline \multicolumn{6}{|l|}{ 2) Lack of strategic planning toward alliance } \\
\hline Commitment level & & 0.796 & & & \\
\hline Fear of future mergers & & 0.689 & & & \\
\hline Legal liability & & 0.672 & & & \\
\hline Loss of opportunity cost & & 0.593 & & & \\
\hline Uneven alliance qualification & & 0.536 & & & \\
\hline Greediness & & 0.514 & & & \\
\hline \multicolumn{6}{|l|}{ 3) Inadequate knowledge about alliance } \\
\hline Inadequate knowledge about alliance & & & 0.780 & & \\
\hline Fear of future failure & & & 0.705 & & \\
\hline Resistance to change from the traditional method & & & 0.422 & & \\
\hline \multicolumn{6}{|l|}{ 4) Managing the alliance } \\
\hline Managerial issues during alliance & & & & 0.818 & \\
\hline Disparities in skills and roles to play in alliance & & & & 0.705 & \\
\hline Staff turnover after alliance & & & & 0.469 & \\
\hline \multicolumn{6}{|c|}{ 5) Different styles of management and cultural values } \\
\hline Different style of management & & & & & 0.916 \\
\hline Different in cultural values & & & & & 0.535 \\
\hline
\end{tabular}

\section{CONCLUSION AND RECOMMENDATIONS}

In the construction industry, entering into a Strategic alliance involves more than just the accomplishment of mutual goals or associates that benefit directly. Strategic alliance adds value to constructing firm's corporate social capital by ensuring exposure to a broad variety of available assets and services managed by representatives of the strategic alliance network. Despite the potential benefits to be gained when construction firms involved in strategic alliance, there are still various barriers facing it in the developing world. This paper was able to assess the awareness level and barriers to the adoption of strategic alliance in the construction industry using Nigeria as a case study. Survey method was fully embraced in the study, using a questionnaire in gathering information from the construction professionals. From the findings, it was discovered that the level of awareness of strategic alliance procurement method among construction professionals is moderately high, which indicated that most construction stakeholders in Nigeria know more about strategic alliance. Therefore, the challenges facing strategic alliance in the construction industry in the developing world is not the awareness/knowledge level, but the commitment of construction firms to enforce it among themselves. Positive perceptions towards SA and willingness to 
embrace it within the construction sector will be a great mechanism to SA implementation in the developing world.

Findings revealed that resistance to change from the traditional method, fear of job loss after alliance and managerial issues during alliance were the most notable barriers facing strategic alliance procurement method in the construction industry. Almost all identified barriers in the literature were agreed by the professionals to be barriers facing strategic alliance in the construction industry in an emerging market. From factor analysis outcome, the barriers were clustered under the following five labels, namely fear and trust issue, lack of strategic planning toward alliance, inadequate knowledge about alliance, managing the alliance, and different in style of management and cultural values as the major component barriers facing SA in the construction industry. A key barrier in all the factors that were analyzed is inadequate knowledge about alliance. Realization of SA existence among the construction organizations affects the level of knowledge and benefits they could derive from its implementation in the construction industry. Therefore, stakeholders in the construction industry need to be well enlightened through conferences, seminars and workshops on how to embrace various forms of alliance within and outside the industry. This research was mainly limited to Nigeria, as the data provided for this study were predominantly from the country. Similar studies can also be fully extended to other developing countries. More so, different measures may be studied in promoting and adoption SA in the building industry, especially by making reference to countries where the exercise has been fully adopted. Further studies can also examine the structural and organizational influence in adopting strategic alliance.

Furthermore, this study recommended that strategy orientation of both construction partners coming to any alliance must be aligned towards a common objective and vision. Also, individual must be ready to strictly adhere with the regulations and rules guiding the alliance. Furthermore, when its required to ensure openness and a better understanding of rift, the structure and form of sharing for profit and financial report should be developed to prevent the fissure and lack of confidence among both the parties. Construction companies in an emerging market have many opportunities to leverage on the knowledge, resources, and skills of other organizations they alliance with through inter-organization agreements even outside the construction industry. So, full implementation of strategic alliance among construction companies and even outside the sector will be a great advantage in exposure to new events and innovations, complementary tools. This will improve the capacity of the company to research, share risks and externalization of different operations. These recommendations will be useful in encouraging SA implementation in Nigeria, and other countries in the developing world with similar approach in project execution.

\section{REFERENCE}

Akiner, I. and Yitmen, I., (2011). International Strategic Alliances in Construction: Performances of Turkish Contracting Firms. in Proc. Management and Innovation for a Sustainable Built Environment Conference, Amsterdam, The Netherlands, June 2011, pp. 20-23

Andersson, M., and Görgulu, I. (2014). Strategic Partnering Relationships in the Swedish Construction Industry - Overview And Case Studies On Structures For Learning. Master's Thesis E2014:069 submitted to Department of Technology Management and Economics Division of Service Management, Chalmers University Of Technology Göteborg, Sweden 2014.

Artto, K. and Kujala, J. (2008). Project Business as a Research Field. International Journal of Managing Projects in Business. 1(4), 469-497

Bamford, James and Ernst, David (2002). Managing an Alliance Portfolio. McKinsey Quarterly, 3, 28-39. 
Bamford, James and Ernst, David (2002). Measuring Alliance Performance. McKinsey Quarterly, 5, 5-17.

Bamford, James and Ernst, David (2005). Governing Joint Ventures: Better over- sight isn't just for Wholly Owned Businesses. Mckinsey Quarterly, Special Edition, pp. 62-69.

Burke, C.M and Morley, M.J (2016). On Temporary Organizations: A Review, Synthesis a Research Agenda. Human Relations 69(6), 1235-1258

Chang, W and Hsin, J (2006). The Study of the Motivation and Performance of the Incubators' Strategic Alliances: Strategic Groups Perspective. Journal of American Academy of Business, Cambridge, 8(2), 126-133

Faems, D. and Van Looy, B. (2003). The role of Inter-Organizational Collaboration within Innovation Strategies: Towards a portfolio approach', Working Paper Steunpunt OOI. pp. $1-12$

Fitzpatrick, W and Dilullo, S (2005). Strategic Alliances and the Management of Intellectual Properties: The Art of the Contract. SAM Advanced Management Journal, 70 (3), 3845.

Grant, R and Baden-Fuller, C (2004). A Knowledge Accessing Theory of Strategic Alliances. Journal of Management Studies, 41(1), 61-84

Gulati, R. (2007). Managing Network Resources: Alliances, Affiliations, and Other Relational Assets, Oxford University Press, Oxford.

Hameed, W., and Abbott, C. (2017). Critical review of the success factors of strategic alliances in the UK construction industry. Conference or Workshop Item.

Hitt, M; Ahlstrom, D; Dacin, M; Levitas, E and Svobodina, L (2004). The Institutional Effects on Strategic Alliance Partner Selection in Transition Economies: China Vs. Russia, Organization Science, 15(2), 173-185

Holt, G., Love, P. and Li, H. (2000). The Learning Organisation: Toward a Paradigm for Mutually Beneficial Strategic Construction Alliances. International Journal of Project Management, 18, 415-421.

Howarth, C.S, Gillin, M. and Bailey, J. (1995). Strategic Alliances: Resource-sharing Strategies for Smart Companies', Australia: Pearson Professional (Australia) Pty. Ltd.

Ingirige, B., and Sexton, M. (2006). Alliances in Construction: Investigating Initiatives and Barriers for long-term Collaboration. Engineering, Construction and Architectural Management, 13(5), 521-535

Išoraitè, M. (2009). Importance of Strategic Alliances in Company's Activity. Intellectual Economics, 1(5), 39-46.

Lahdenperä, P. (2009). Project alliance the competitive single target-cost approach. In VTT Tiedotteita - Valtion Teknillinen Tutkimuskeskus.

Love P., Huang J., and Edwards D., (2004). Nurturing a Learning Organization in Construction: A focus on Strategic Shift, Organizational Transformation, Customer Orientation and Quality Centered Learning. Construction Innovation. 4, 113-126

Lui and Ngo (2004). The Role of Trust and Contractual Safeguards on Cooperation and NonEquity Alliances. Journal of Management. 30, 471- 485.

Mills, A., Nalewaik, A., and Davis, P. (2016). Identifying Cultures in Construction Project Alliances. PAQS 2016, Christchurch, New Zealand.

Ngowi, A. (2007). The role of trustworthiness in the formation and governance of construction alliances. Building and Environment, 42(4), 1828-1835.

Nguyen, N. (2019). Performance Evaluation in Strategic Alliances : A Case of Vietnamese Construction Industry. Global Journal of Flexible Systems Management, 1-16

Nielsen, L. and Neergaard, P. (2018). Value Creation from Strategic Partnerships Between Companies and NGOs. Developments in Corporate Governance and Responsibility, 24, $3-12$. 
Nurullah G., Alayoglu, N., and Oyku, N. (2012). A Conceptual Model Proposal for Determinants, Form, Functions and Structure Choice in Strategic Alliances. Procedia Social and Behavioral Sciences. 58, 1594-1600.

Ofori, G. (2000). Globalization and Construction Industry Development: research opportunities. Construction Management and Economics.18, 257-262

Pallant, J. (2005), SPSS Survival Manual: A Step-by-Step Guide to Data Analysis Using SPSS for Windows (Version 12), 2nd ed., Allen \& Unwin, Crows Nest NSW.

Pekkinen L (2010). Risk Management in Project Network. In: Aramo-Immonen H, Naaranoja $\mathrm{M}$ and Toikka $\mathrm{T}$ (eds) Project knowledge sharing arena. Project Management Association Finland (PMAF) in collaboration with University Consortium of Pori (UCP) and University of Applied Sciences in Vaasa (VAMK), Espoo, Finland: $84-100$

Pekuri A, Haapasalo H and Herrala M (2011). Productivity and Performance ManagementManagerial Practices in the Construction Industry. International Journal of Performance Measurement. 1(1), 39-58

Schoorman, F. D., Mayer, R. C., and Davis, J. H. (2005). An Integrative Model of Organizational Trust: Past, Present and Future. Academy of Management Review. 32, 344-354.

Stanek M.B. (2004), Measuring Alliance Value and Risk: A Model Approach to Prioritising Alliance Projects, Management Decision. 42 (2), 182-204

Sushil, S. and Verma, N. (2010). Questionnaire validation made easy. European Journal of Scientific Research. 46(2), 172-178

Tavallaei, R., Hosseinalipour, M., and Mohebifar, A. (2017). 08-Key Factors Affecting Learning through Construction Industry's International Strategic Alliances. Journal of Applied Environmental and Biological Sciences. 7 (7), 80-90.

Van den Berg, M. and Kamminga, P. (2006). Optimising Contracting for Alliances in Infrastructure Projects. International Construction Law Review. 23, 59-77.

Xu, T., Bower, D. A., and Smith, N. J. (2005). Types of collaboration between foreign contractors and their Chinese partners. International Journal. Project Management. 23(1), 45-55

Yi Wei (2007). Factors influencing the success of virtual cooperation within Dutch - Chinese strategic alliances. Doctoral dissertation, University of twente,

Zamir, Z., Sahar, A., and Zafar, F. (2014). Strategic alliances; a comparative analysis of successful alliances in large and medium scale enterprises around the world. Educational Research International, 3(1), 25-39. Retrieved from http://www.erint.savap.org.pk/PDF/Vol.3(1)/ERInt.2014(3.1-03).pdf 